\title{
Temporal coding and study-phase retrieval in young and elderly adults
}

\author{
P. D. McCORMACK \\ Carleton University, Ottawa, Ontario K1S 5B6, Canada
}

\begin{abstract}
It follows from the study-phase retrieval model of Tzeng and Cotton (1980) that age differences favoring young over elderly subjects should be revealed in a recency-judgment task. It may also be predicted from their "availability-principle" notion that the two sets of age functions relating accuracy of recency judgments to distance between test items (lag) will be parallel. Young and elderly females made recency judgments at lags of $0,12,24$, and 36 intervening items. Performance improved as a function of lag, the young were more accurate than the elderly, and the two sets of lag functions were parallel.
\end{abstract}

Tzeng and Cotton (1980) propose a study-phase retrieval model in which they assert that the coding of items during the study phase of a recency-judgment task entails rehearsal of earlier items in the list, and that it is these joint study-phase rehearsals and retrievals that permit temporal coding of relative serial order. The effectiveness of this process is assumed to depend heavily on practice in memory skills and, hence, should be developmentally sensitive. Since the elderly show rehearsal deficiencies (see Craik, 1977; Eysenck, 1977; Hasher \& Zacks, 1979), and since they have not received much, if any, recent practice on memory tasks, they would be expected to be at a disadvantage relative to a group of college students. It follows, then, that age differences favoring younger subjects should be revealed in a recency-judgment task. This has not, however, been the case when pictorial materials have been used (Perlmutter, Metzger, Nezworski, \& Miller, 1981) or when memory for serial location has been investigated (McCormack, 1981). In these two studies, the elderly performed at a level equivalent to that of the young. The purpose of the present experiment was to test the Tzeng and Cotton (1980) notion by having young and elderly subjects make recency judgments in the presence of word pairs.

This was done in conjunction with a manipulation of distance, or lag, between test items. It is now a well established fact that accuracy of recency judgments is an increasing function of lag (Flexser \& Bower, 1974; Fozard, 1970; Galbraith, 1975; Guenther \& Linton, 1975; Lockhart, 1969; Perlmutter et al., 1981; Tzeng \& Cotton, 1980; Tzeng, Lee, \& Wetzel, 1979; Underwood, 1977; Underwood \& Malmi, 1978a, 1978b; Yntema \&

This study was funded by the Natural Sciences and Engineering Research Council of Canada, Grant A7498. The author wishes to acknowledge the assistance of Anne Marie Ellis and of Elizabeth Kristjansson for testing the subjects. Requests for reprints should be sent to P.D. McCormack, Department of Psychology, Carleton University, Ottawa, Ontario K1S 5B6, Canada.
Trask, 1963). There have been various theoretical attempts to account for this phenomenon (e.g., Morton, 1968; Peterson, 1967; Yntema \& Trask, 1963). The only one that appears to have any direct relevance to an age manipulation is the "availability principle" of Tzeng and Cotton (1980). According to this position, when the subject is confronted with a test pair, a recency judgment is facilitated by a successful discovery of a third item that occurred between the two members of the pair during the study phase. This, of course, would be most likely for long-lag items. This theoretical notion is employed by Tzeng and Cotton (1980) in conjunction with the study-phase retrieval model, with the additional assumption that the effects of lag and of rehearsals on temporal coding are produced by two independent sources. The prediction, therefore, is that the lag functions for the young and elderly will be parallel. Another purpose of the present experiment was to test this prediction.

\section{METHOD}

\section{Subjects}

One hundred females participated in the experiment. Fifty of these were elderly, with a mean age of 68.3 years and an age range from 59 to 76 years. They were obtained from a subject pool described elsewhere (McCormack, 1981). The remaining 50 females had a mean age of 21.2 years, with an age range from 17 to 29 years. All were obtained from introductory psychology classes.

\footnotetext{
Materials and Apparatus

Sixty nouns were selected from the norms of Paivio, Yuille, and Madigan (1968). Their mean imagery, concreteness, and meaningfulness values (with standard deviations in parentheses) were as follows: $6.28(.56), 6.41(1.21), 6.79(.79)$. A computer program was written to create a different random order of the 60 words for each of the 50 elderly subjects. The first and last five items served as primacy and recency buffers, respectively. The program also generated 16 pairs of words for recency judgments, four at each of lags of $0,12,24$, and 36 intervening items. This was done randomly and on an individual basis. The positions of the words in each pair were also randomized. The $\mathbf{5 0}$ young subjects were yoked to their elderly counterparts in the sense that the two sets of computer printouts were identical.
} 
Procedure

The elderly were tested in their homes, and the young were tested in the laboratory. In the study phase, the 60 words were presented individually for about $5 \mathrm{sec}$ each. The subject was instructed to study each word for a later recency-judgment test. The test phase began approximately $3 \mathrm{~min}$ after the study phase, at which time the two words were read aloud, with the subject attempting to name the most recently encountered item. The entire session took about $20 \mathrm{~min}$.

\section{RESULTS AND DISCUSSION}

An analysis of variance for a 2 (young vs. elderly) by 4 (lag) design, with the first factor as a between-subjects measure and the second as a repeated measure, was performed on the number of correct recency judgments. These data, represented in terms of proportions correct, are depicted in Figure 1. The lag main effect was significant, as would be expected $[F(3,294)=17.83$, $\mathrm{p}<.001]$. The main effect of age was also significant $[F(1,98)=7.84, p<.01]$, the mean number of correct recency judgments, collapsed over the four lag conditions, for the young and elderly being 10.48 and 9.40 , respectively, the maximum number correct being 16 . The age difference was in accordance with the studyphase retrieval model, the elderly presumably having a more difficult time with joint study-phase retrievals and rehearsals. The Lag by Age interaction was not significant $[F(3,294)<1]$. Since the effects of rehearsals and lag are assumed by Tzeng and Cotton (1980) to be independent, the parallel functions of Figure 1 are also in accordance with the model.

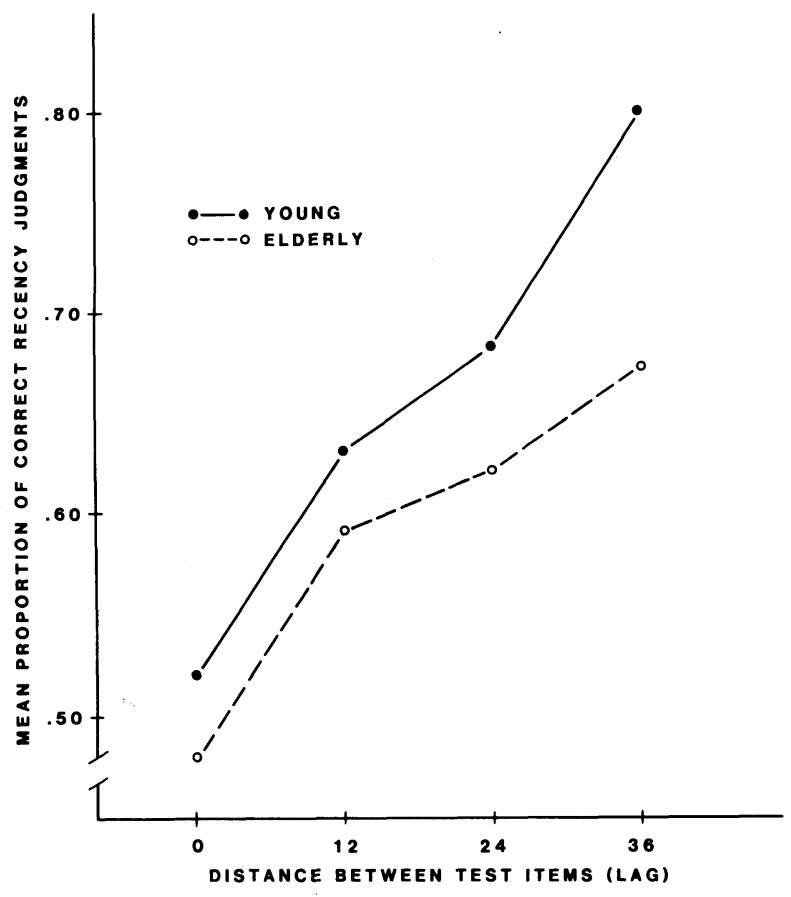

Figure 1. Mean proportion of correct recency judgments as a function of lag.
The frequency of choice of the second member of the test pair was subjected to analysis; the means for the young and elderly were 8.88 and 9.14 , respectively, and the difference was not significant $[\mathrm{t}(98)=1.37$, $.10<\mathrm{p}<.20]$. The mean overall frequency of choice was 9.01 , which was reliably greater than the expected value of $8.00[\mathrm{t}(99)=4.59, \mathrm{p}<.001]$. There was, therefore, a bias to select the second member of the pair during the test phase of the experiment. This was, however, not more likely to occur for one age group than for the other. Had this been the case, the data would have been contaminated and, consequently, extremely difficult to interpret. This problem has arisen before (McCormack, 1981).

\section{REFERENCES}

Craik, F. I. M. Age differences in human memory. In J. E. Birren \& K. W. Schaie (Eds.), Handbook of the psychology of aging. New York: Van Nostrand Reinhold, 1977.

EySENCK, M. Human memory: Theory, research and individual differences. Oxford: Pergamon Press, 1977.

Flexser, A. J., \& Bower, G. H. How frequency affects recency judgments: A model for recency discrimination. Journal of Experimental Psychology, 1974, 103, 706-716.

Fozard, J. L. Apparent recency of unrelated pictures and nouns presented in the same sequence. Journal of Experimental Psychology, 1970, 86, 137-143.

Galbraith, R. C. A developmental investigation of the independence of attributes of memory. Unpublished doctoral dissertation, Northwestern University, Evanston, Ill., 1975.

Guenther, R. K., \& Linton, M. Mechanisms of temporal coding. Journal of Experimental Psychology: Human Learning and Memory, 1975, 1, 182-187.

HAsher, L., \& ZACKs, R. T. Automatic and effortful processes in memory. Journal of Experimental Psychology: General, 1977, 108, 356-388.

LockнART, R. S. Recency discrimination predicted from absolute lag judgments. Perception \& Psychophysics, 1969, 6, 42-44.

McCormACK, P. D. Temporal coding by young and elderly adults: A test of the Hasher-Zacks model. Developmental Psychology, $1981,17,509-515$.

Morton, J. Repeated items and decay in memory. Psychonomic Science, 1968, 10, 219-220.

Paivio, A., Yuille, J. C., \& Madigan, S. A. Concreteness, imagery, and meaningfulness values for 925 nouns. Journal of Experimental Psychology Monograph Supplement, 1968, 76(1, Pt. 2).

Perlmutter, M., Metzger, R., Nezworski, T., \& Miller, K. Spatial and temporal memory in 20 and 60 year olds. Journal of Gerontology, 1981, 36, 59-65.

Peterson, L. R. Search and judgment in memory. In B. Kleinmuntz (Ed.), Concepts and the structure of memory. New York: Wiley, 1967.

Tzeng, O. J. L., \& Cotton, B. A study-phase retrieval model of temporal coding. Journal of Experimental Psychology: Human Learning and Memory, 1980, 6, 705-716.

Tzeng, O. J. L., Lee, A. T., \& WetzeL, C. D. Temporal coding in verbal information processing. Journal of Experimental Psychology: Human Learning and Memory, 1979, 5, 52-64.

UNDERWOOD, B. J. Temporal codes for memories: Issues and problems. New York: Erlbaum, 1977.

UNDERWOOD, B. J., \& MALmi, R. A. An evaluation of measures used in studying temporal codes for words within a list. Journal of Verbal Learning and Verbal Behavior, 1978, 17, 279-293. (a) 
Unde Rwood, B. J., \& Malmi, R. A. Transfer from recency learning to corresponding two-category classification learning. Bulletin of the Psychonomic Society, 1978, 11, 200-202. (b) YNTema, D. B., \& Trask, F. P. Recall as a search process.
Journal of Verbal Learning and Verbal Behavior, 1963, 2 , 65-74.

(Received for publication September 24, 1982.) 